\title{
Molecular Analysis of Italian Patients with Congenital Glaucoma
}

\author{
Italo Giuffre' \\ Dept. of Ophthalmology and Otorhinolaryngology-Medical School-Catholic \\ University of Roma \\ Italy
}

\section{Introduction}

Glaucoma is a heterogeneous group of optic neuropathies which can lead to optic nerve loss of optic nerve fibers and permanent loss of vision. It is the second most prevalent cause of bilateral blindness in the Western World and it affects several million people worldwide. (Ray et al., 2003). There are different types of glaucoma: adult-onset open-angle glaucoma, the commonest form of the disease, representing almost half of all cases; as juvenile-onset open-angle glaucoma, followed by juvenile-onset open-angle glaucoma (Weisschuh and Schiefer, 2003), and as congenital glaucoma (CG), a clinical and genetic entity distinct from the juvenile form.

CG may be associated with ocular malformation, such as aniridia (Lee et al., 2003) or congenital hydrocephalus and anterior segment dysgenesis (Mandal et al., 2002). It results from poorly understood developmental abnormalities of the ocular drainage structures and is clinically characterized by high intraocular pressure (IOP), epiphora, corneal oedema, photophobia, blepharospasm and ocular enlargement (Libby et al., 2003). The disease is bilateral in approximately $75 \%$ of cases. CG incidence varies substantially among countries: it is estimated to occur in 1/10,000 births in Europe, in 1/2500 in Saudi Arabia and 1/1250 in the gypsy population of Slovakia. (Online Mendelian Inheritance in Man, OMIM 231300).

An increase in IOP, untreated either with surgery or pharmacological therapy, results in ocular enlargement (buphthalmos) and rapidly progressive cupping of the optic nerve with severe and irreversible alteration of the visual field (Belmouden et al., 2002, Bruttini et al., 2003). Early recognition and therapy can significantly improve the child's visual function. Onset of an aggressive form of glaucoma occurs between birth and 3 years of age. The disease has higher prevalence in males $(2: 1 \mathrm{M} / \mathrm{F})$.

Most cases of CG are sporadic and recessive inheritance of CG is common, with almost complete penetrance in populations with a high consanguinity rate. Reduced penetrance ( $40 \%$ in some populations) and various phenotypic forms suggests a polygenic inheritance pattern or multifactorial aetiologies.

Genetic linkage studies, started in 1995, identified two separate loci (GLC3A on 2p21 and GLC3B on 1p36) associated with the disease, thus confirming that CG is genetically heterogeneous (Ohtake et al., 2003) (Sarfarazi et al., 1995). A few years later Sarfarazi reported that the cytochrome P4501B1 gene (CYP1B1, OMIM 601771), located within the GLC3A locus, was mutated in individuals with CG (Akarsu et al., 1996). 
CYP1B1 belongs to a multigene superfamily of monomeric mixed-function monooxygenases, responsible for the phase I metabolism of a wide range of structurally different substrates including steroids and retinoids (Stoilov et al., 1996, Hayes et al., 1997). A specific CYP1B1 metabolite is most probably required for normal eye development, and its deficiency (or toxic accumulation) may result in CG (Zhang et al., 2000).

The CYP1B1 gene maps to 2p22-p21, contains 3 exons and 2 introns, and is expressed in several normal human tissues (Stoilov et al., 2001). Northern hybridization analysis showed strong expression of CYP1B1 in the anterior uveal tract, which is involved in secretion of the aqueous humor and in the regulation of outflow facility, processes that could contribute to the elevated intraocular pressure characteristic of CG (Sutter et al., 1994).

An extensive allelic heterogeneity was illustrated by a comprehensive sequence analysis of the translated regions of the CYP1B1 gene in 22 CG families and in 100 randomly selected normal individuals. Sixteen mutations and 6 polymorphisms were identified. The positions affected by these changes were evaluated by building a 3-dimensional homology model of the conserved C-terminal half of CYP1B1. These mutations may interfere with the heme incorporation by affecting the hinge region and/or the conserved core structures (CCS) that determine the proper folding and heme-binding ability of P450 molecules. In contrast, all polymorphic sites were poorly conserved and located outside the CCS (Stoilov et al., 1998). More than 50 CYP1B1 pathogenic mutations, including 34 missense/nonsense substitutions, 10 small deletions, 6 small insertions, a 27 bp duplication and a deletion involving part of intron 2 and exon 3, have been described in various ethnic groups (Human Gene Mutations Database). Two CYP1B1 mutations, Met1Thr and Trp57Stop, in a compound heterozygosis status, have been identified as the molecular basis of Peters' anomaly that consists of corneal opacity, defects in the posterior structures of the cornea, iridocorneal and/or keratolenticular adhesions (Stoilov et al., 1998).

Mutations in CYP1B1 were found also in patients with juvenile glaucoma (JOAG), an earlyonset form of open angle glaucoma that can be caused by a mutation in the gene encoding myocilin (MYOC/TIGR).

Vincent et al. studied the role of the CYP1B1 and MYOC/TIGR and found that MYOC/TIGR mutations included cases of juvenile glaucoma (either with or without pigmentary glaucoma) and mixed-mechanism glaucoma, and CYP1B1 mutations involved cases of juvenile open-angle glaucoma as well as cases of congenital glaucoma. That paper emphasized the genetic heterogeneity of juvenile and congenital glaucoma and demonstrated that the spectrum of expression of MYOC/ TIGR and CYP1B1 mutations is greater than expected. It also appeared that CYP1B1 may act as a modifier of MYOC/ TIGR expression and that these 2 genes may interact through a common pathway (Vincent et al., 2001). Both CYP1B1 and the MYOC/TIGR genes are expressed in the iris, trabecular meshwork, and ciliary body of the eye (Vincent et al., 2002).

Different CYP1B1 mutations together with a common MYOC/TIGR mutation (Gln48His) have been reported in CG patients (Ming and Muenke, 2002, Chakrabarti et al., 2005), thus suggesting a role for the MYOC gene in congenital glaucoma via digenic interactions with CYP1B1.

In 22 Saudi Arabian families, 40 apparently unaffected individuals had mutations in CYP1B1 and haplotypes identical to their affected siblings. Analysis of these relatives suggested the presence of a dominant modifier locus that is not linked genetically to CYP1B1. Linkage and Southern analyses excluded 3 candidate modifier loci, the arylhydrocarbon receptor (AHR) on $7 \mathrm{p} 15$, the arylhydrocarbon receptor nuclear translocator 
(ARNT) on 1q21, and the CYP2D6 gene on 22q13.1 (Kaur et al., 2005, Bejjani et al., 2000, Libby et al., 2003).

To determine the possible role of the genetic defects described in CG cases in Italy, molecular analysis was undertaken, and the CYP1B1 and MYOC genes were screened for mutations. We describe here the pathogenic mutations found, some of which are not published, and the haplotype for five intragenic SNPs (Single Nucleotide Polymorphisms) associated with the mutations identified.

\section{Methods}

\subsection{Subjects}

Peripheral blood samples were collected from 72 patients ( 10 subjects belonging to 5 families and 62 unrelated subjects) with a diagnosis of bilateral CG coming from different Italian regions. A clinical report with demographic data and clinical evaluation was obtained for every patient. Reports contain subjective symptoms (irritability, sensitivity to light, tearing of the eyes) and objective evaluation (corneal diameter enlargement, type of corneal oedema, rupture of Descemet membrane, increase of IOP). Age of disease onset and number of surgical procedures are described in Table I.

\begin{tabular}{|c|c|c|c|c|c|c|c|c|}
\hline ID & $\begin{array}{c}\text { Age at } \\
\text { Diagnosis } \\
\text { (mo) }\end{array}$ & $\begin{array}{c}\mathrm{N}^{\circ} \text { of } \\
\text { Surgery } \\
\text { events }\end{array}$ & Genotype & $\begin{array}{c}\text { SNP } \\
2\end{array}$ & $\begin{array}{c}\text { SNP } \\
3\end{array}$ & $\begin{array}{c}\text { SNP } \\
4\end{array}$ & $\begin{array}{c}\mathrm{SNP} \\
5\end{array}$ & $\mid \begin{array}{c}\mathrm{SNP} \\
6\end{array}$ \\
\hline 206 & 1 & 6 & [L52P] / [R390S] & $\mathrm{C} / \mathrm{G}$ & G/T & $\mathrm{G} / \mathrm{C}$ & $\mathrm{T} / \mathrm{C}$ & A \\
\hline 110 & 1 & 4 & [A106D] / [A106D] & $\mathrm{C}$ & G & G & $\mathrm{T}$ & A \\
\hline 161 & $<1$ & 3 & [1236-1237insC] / [1436-1448del13] & $\mathrm{C}$ & G & G & $\mathrm{T}$ & $\mathrm{A}$ \\
\hline 164 & $<1$ & 3 & [A106D] / [1775-1801dup27] & $\mathrm{C}$ & G & G & $\mathrm{T}$ & $\mathrm{A}$ \\
\hline 113 & 1 & 3 & [1436-1448del13] / - & $\mathrm{C}$ & G & G & $\mathrm{T}$ & $\mathrm{A}$ \\
\hline 2 & 1 & 2 & [W57X] / [1775-1801dup27] & $\mathrm{C}$ & G & G & $\mathrm{T}$ & $\mathrm{A}$ \\
\hline 67 & 1 & 2 & [G61E] / [1436-1448del13] & $\mathrm{C}$ & G & G & $\mathrm{T}$ & A \\
\hline 71 & 1 & 2 & [1236-1237insC] / [1775-1801dup27] & $\mathrm{C}$ & G & G & $\mathrm{T}$ & A \\
\hline 153 & $<1$ & 2 & [G61E] / [1436-1448del13] & $\mathrm{C}$ & G & G & $\mathrm{T}$ & $\mathrm{A}$ \\
\hline 12 & 2 & 4 & [G61E] / [1236-1237insC] & $\mathrm{C}$ & G & G & $\mathrm{T}$ & A \\
\hline 25 & 3 & 8 & [1775-1801dup27] / [1775-1801dup27] & $\mathrm{C}$ & G & G & $\mathrm{T}$ & A \\
\hline 42 & 3 & 7 & [G61E] / - * & C & G & G/C & $\mathrm{T} / \mathrm{C}$ & $A / G$ \\
\hline 63 & 5 & 3 & {$[\mathrm{R} 355 \mathrm{X}] /[\mathrm{E} 387 \mathrm{~K}]$} & $\mathrm{C} / \mathrm{G}$ & G/T & G/C & $\mathrm{T} / \mathrm{C}$ & A \\
\hline 1 & 5 & 2 & [W57X] / [1775-1801dup27] & $\mathrm{C}$ & G & G & $\mathrm{T}$ & A \\
\hline 16 & 6 & 2 & {$[\mathrm{~L} 26 \mathrm{R}] /[\mathrm{R} 368 \mathrm{H}]$} & $\mathrm{C}$ & G & G & $\mathrm{T}$ & $\mathrm{A}$ \\
\hline 203 & 8 & 3 & {$[\mathrm{~A} 443 \mathrm{G}] /$ - } & C/G & G/T & G & $\mathrm{T}$ & A \\
\hline 31 & $<1$ & 1 & [G61E] / [P52L] & $\mathrm{C}$ & G & G & $\mathrm{T}$ & A \\
\hline 54 & 1 & 1 & {$[\mathrm{M} 1 \mathrm{~T}] /[\mathrm{R} 368 \mathrm{H}]$} & $\mathrm{C}$ & G & G & $\mathrm{T}$ & A \\
\hline 62 & 12 & 0 & {$[\mathrm{R} 355 \mathrm{X}] /[\mathrm{E} 387 \mathrm{~K}]$} & $\mathrm{C} / \mathrm{G}$ & G/T & $\mathrm{G} / \mathrm{C}$ & $\mathrm{T} / \mathrm{C}$ & $\mathrm{A}$ \\
\hline 89 & $<1$ & 0 & [G61E] / [1236-1237insC] & $\mathrm{C}$ & G & G & $\mathrm{T}$ & $\mathrm{A}$ \\
\hline 122 & $17 \mathrm{y}$ & 0 & [G61E] / [G61E] & $\mathrm{C}$ & G & G & $\mathrm{T}$ & A \\
\hline 179 & $<1$ & 0 & [A237E] / [1581-1582ins10] & $\mathrm{C}$ & G & $\mathrm{C}$ & $\mathrm{T}$ & A \\
\hline 91 & $4 \mathrm{y}$ & 0 & [1236-1237insC] / - & $\mathrm{C}$ & G & $G / C$ & $\mathrm{~T} / \mathrm{C}$ & A \\
\hline 114 & $29 \mathrm{y}$ & 0 & [1436-1448del13] / - & $\mathrm{C}$ & G & G & $\mathrm{T}$ & $\mathrm{A}$ \\
\hline 132 & $3 \mathrm{y}$ & 0 & [G61E] / - & $\mathrm{C}$ & G & $G / C$ & $\mathrm{~T} / \mathrm{C}$ & $\mathrm{A} / \mathrm{G}$ \\
\hline
\end{tabular}

Table I. Phenotype-Genotype Correlation in Italian CG patients with CYP1B1 mutations. SNP 1-5 are: 1. 3947 C >G (R48G); 2. 4160 G>T (A119S); 3. 8131C >G (L432V); 4. 8184C $>$ T (D449D); 5. 8195A>G (N435S). 


\subsection{Mutation screening}

DNA was extracted from peripheral blood of patients and family members. The entire transcript region of the CYP1B1 gene, organized in three exons of which only II and III are translated, was screened for mutations using four sets of primers:

set1 - cyp1b1Ex1F 5'-GCT TTG ACT CTG GAG TGG G-3'and cyp1b1Ex1R 5'-TCC ATC TGA AGA GGT CGC C-3' (424 bp); set2 - cyp1b1Ex2aF 5'-TGA GTG TCA CGC CTT CTC C-3' and cyp1b1Ex2aR 5'-CTC AGC ACG TGG CCC TC-3' (548 bp); set3 - cyp1b1Ex2bF 5'-ATG CGC AAC TTC TTC ACG-3' and cyp1b1Ex2bR 5'-AGA GGA GAA AAG ACC TGG C-3' (631 bp); set4 - cyp1b1Ex3F 5'-TGC TCA CTT GCT TTT CTC TC-3' and cyp1b1Ex3R 5'-ATT TTA CTC CTC ATC TCC GAA-3' (691 bp). Polymerase chain reaction (PCR) amplification was performed in a $50-\mu \mathrm{L}$ volume consisting of 50 to $100 \mathrm{ng}$ genomic DNA, $10 \mathrm{mM}$ Tris- $\mathrm{HCl}$ ( $\mathrm{pH}$ 8.3), $50 \mathrm{mM} \mathrm{KCl}, 1.5 \mathrm{mM} \mathrm{MgCl} 2,0.2 \mathrm{mM}$ dNTPs, $0.8 \mathrm{M}$ of each primer and $1 \mathrm{U}$ Taq polymerase (AmpliTaq Polimerase - Perkin Elmer) with 10\% dimethyl sulfoxide (DMSO) only for set 2 and set 3 . PCR amplification procedures were performed under the following conditions: for set 1 and set 4,2 cycles consisting of 60 seconds at $94^{\circ} \mathrm{C}, 30$ seconds at $52^{\circ} \mathrm{C}$ and 90 seconds at $72^{\circ} \mathrm{C}$ followed by 35 cycles each consisting of 30 seconds at $94^{\circ} \mathrm{C}, 30$ seconds at $54^{\circ} \mathrm{C}$ and 90 seconds at $72^{\circ} \mathrm{C}$, followed by a final extension of 7 minutes at $72^{\circ} \mathrm{C}$; for set 2 and set 3,12 cycles consisting of 60 seconds at $94^{\circ} \mathrm{C}, 120$ seconds at $64^{\circ} \mathrm{C}$ with a decrement of $1^{\circ} \mathrm{C}$ every cycle and 180 seconds at $72^{\circ} \mathrm{C}$ followed by 25 cycles each consisting of 60 seconds at $94^{\circ} \mathrm{C}, 120$ seconds at $52^{\circ} \mathrm{C}$ and 5 minutes at $72^{\circ} \mathrm{C}$, followed by a final extension of 7 minutes at $72^{\circ} \mathrm{C}$.

Patients with none or only one mutation in the CYP1B1 gene were screened for mutations in the transcript region of the MYOC/TIGR gene using three sets of primers:

Set 1 - myocEx1F 5'-GGC TGG CTC CCC AGT ATA TA - 3'and myoc1Ex1R 5'-CTG CTG AAC TCA GAG TCC CC- 3' ( 760 bp); set 2 - myocEx2F 5'-AAC ATA GTC AAT CCT TGG GCC- 3' and myocEx2R 5'- TAA AGA CCA TGT GGG CAC AA- 3' ( 230 bp); set 3 myocEx3F 5'-TTA TGG ATT AAG TGG TGC TTC G- 3' and myocEx3R 5'- AGC ATC TCC TTC TGC CAT TG- 3' (870 bp). PCR amplification was performed in a $25-\mu \mathrm{L}$ volume consisting of 50 to $100 \mathrm{ng}$ genomic DNA, $10 \mathrm{mM}$ Tris- $\mathrm{HCl}$ (pH 8.3), $50 \mathrm{mM} \mathrm{KCl}, 1.5 \mathrm{mM}$ $\mathrm{MgCl}_{2}, 0.2 \mathrm{mM}$ dNTPs, $0.8 \mathrm{M}$ of each primer and $1 \mathrm{U}$ Taq polymerase (AmpliTaq Polimerase - Perkin Elmer). PCR amplification procedures were performed as follows: 35 cycles consisting of 60 seconds at $94^{\circ} \mathrm{C}, 60$ seconds at $55^{\circ} \mathrm{C}$ and 120 seconds at $72^{\circ} \mathrm{C}$ followed by a final extension of 7 minutes at $72^{\circ} \mathrm{C}$.

PCR products were sequenced on an automated DNA sequencer (ABI-310; PE Applied Biosystems).

Every nucleotide change is indicated using the sequence of the cDNA published with the accession number NM_000104.2 for the CYP1B1 and NM_000261 for the MYOC/TIGR transcript. The position of mutations were described as in Recommendations for a Nomenclature System for Human Gene Mutations (Antonarakis et al., 1998).

\subsection{Comparative sequencing alignment}

The cytochrome P4501B1 and MYOC/TIGR sequences were obtained from GenBank provided by the National Center for Biotechnology Information, Bethesda, MD, USA (http://ww.ncbi.nlm.nih.gov/Genbank).

Computer-assisted sequence alignment was performed with the pattern-induced multisequence alignment program (PIMA; provided by Baylor College of Medicine Search Launcher and available at: http://searchlauncher.bcm.tmc.edu). 


\section{Results}

\subsection{CYP1B1 gene sequence analysis}

Twenty-five patients $(34,7 \%)$ were carriers of mutations in the coding region of CYP1B1 gene: 17 were compound heterozygotes, 2 were homozygotes, 6 carried only one mutation in a single allele (Table II).

The analysis was also performed on relatives of mutated subjects in order to verify the allele segregation and to complete the family study.

\begin{tabular}{|c|c|c|c|c|}
\hline Exon & & Effect & Patients & $\begin{array}{c}\mathrm{N}(\%) \text { of } \\
\text { affected } \\
\text { chromosomes } \\
(\mathrm{n}=44)\end{array}$ \\
\hline 2 & $\mathrm{~T} 374 \mathrm{C}$ & M1T & 54 & $1(2.3 \%)$ \\
\hline 2 & T449G & $\mathrm{L}^{26 \mathrm{R} \wedge}$ & 16 & $1(2.3 \%)$ \\
\hline 2 & C527T & P52L*^ & 31,206 & $2(4.5 \%)$ \\
\hline 2 & G543A & W57X & 1,2 & $2(4.5 \%)$ \\
\hline 2 & G554A & G61E & $\begin{array}{l}12,31,67,89,122,153 \\
42,131\end{array}$ & $9(20.5 \%)$ \\
\hline 2 & C689A & $\mathrm{A}^{106 D^{\wedge}}$ & 110,164 & $3(6.8 \%)$ \\
\hline 2 & C1082A & $\mathrm{A} 237 \mathrm{E}^{\wedge}$ & 179 & $1(2.3 \%)$ \\
\hline 2 & 1236-1237insC & $\begin{array}{c}\text { Frameshit beginning } \\
\text { from aa } 288\end{array}$ & $12,71,89,91,161$ & $5(11.4 \%)$ \\
\hline 3 & C1435T & R355X & 62,63 & $2(4.5 \%)$ \\
\hline 3 & 1436-1448del13 & $\begin{array}{c}\text { Frameshit beginning } \\
\text { from aa } 355\end{array}$ & $67,113,114,153,161$ & $5(11.4 \%)$ \\
\hline 3 & G1475A & $\mathrm{R} 368 \mathrm{H}$ & 16,31 & $2(4.5 \%)$ \\
\hline 3 & G1531A & E387K & 62,63 & $2(4.5 \%)$ \\
\hline 3 & C1540A & R390S & 206 & $1(2.3 \%)$ \\
\hline 3 & 1581-1582ins10 & $\begin{array}{l}\text { Frameshit beginning } \\
\text { from aa } 404\end{array}$ & 179 & $1(2.3 \%)$ \\
\hline 3 & T1692G & $\mathrm{F} 440 \mathrm{~L}^{* \wedge}$ & 31,206 & \\
\hline 3 & C1700G & A443G & 203 & $1(2.3 \%)$ \\
\hline 3 & 1775-1801dup27 & $\begin{array}{c}\text { Frameshit beginning } \\
\text { from aa } 468\end{array}$ & $1,2,25,71,164$ & $6(13.6 \%)$ \\
\hline
\end{tabular}

* present on the same chromosome inherited from the unaffected father, in patients 31 and 206 who are also compound heterozygotes for other published pathological mutations (G61E and R390S

respectively).

$\wedge$ new variations

Table II. Frequencies of CYP1B1 mutations in the Italian population

Out of the seventeen different CYP1B1 variations identified, twelve had been previously characterized as pathogenetic: six aminoacid substitutions (M1T, G61E, R368H, E387K, R390S and A443G), two stop codons (W57X, R355X), two insertions (1236-1237insC and 
1581-1582ins TCATGCCACC), one deletion (1436-1448delGAGTGCAGGCAGA) and one duplication (1775-1801dupGGCGGTGCATTGGCGAAGAACTTTCTA). Five variations (L26R, P52L, A106D, A237E, F440L) are described here for the first time (Table II).

The new variants show the following characteristics: L26R, which affects the second nucleotide of codon 26, substitutes leucine, an aliphatic and hydrophobic residue with a polar and hydrophilic arginine. The variation L26R is present in patient 16 with the known mutation R368H. A237E presents a substitution of an alanine, weakly hydrophobic with small nonpolar side chains, with glutamic acid that carries a hydrophilic acidic group with strong negative charge and was found in patient 179 associated with the insertion 1581-1582ins10.

A106D was observed on three CG chromosomes (patient 110 is homozygous and patient 164 is compound heterozygote with the known mutation 1775-1801dup27). This change causes a missense substitution of alanine (weakly hydrophobic with small nonpolar side chains) with asparagine (with polar, uncharged side chains).

P52L changes proline, often present in the protein turning point and with small nonpolar side chains, to leucine (aliphatic and hydrophobic). F440L changes phenylalanine, a hydrophobic aminoacid usually orientated towards the interior of the folded protein, to leucine with the same characteristics as phenylalanine.

The variations P52L and F440L are present in cis in patients 31 and 206, who are also compound heterozygotes for other published pathological mutations (G61E and R390S respectively); these patients are from the same Italian region.

All new identified aminoacidic changes alter residues that are evolutionarily conserved in Eukariota and in the cytochrome P450 family (Figs. \# 1 and 2).

The most frequent mutations in our CG patients are G61E, 1775-1801dup27, 1436-1448del13 and $1236-1237$ insC; they occur respectively in $20.5 \%, 13.6 \%, 11.4 \%$ and $11,4 \%$ of mutated chromosomes (Table II).

Two nucleotide variants were found in the untranslated exon 1: one of these (cDNA $198 \mathrm{C} / \mathrm{T})$ was characterized as a single nucleotide polymorphism (NCBI SNPs databank rs 9341244) while the second one (C>A at 226 of cDNA) was identified for the first time in patient 91.

In these 72 Italian CG subjects we also identified 6 Single Nucleotide Polymorphisms previously described and 2 new synonymous changes (G/A 359E and C/T 363V) whose frequencies are $1 / 144$ and $3 / 144$ respectively.

\subsection{CYP1B1 SNP haplotypes}

We analyzed the following known CYP1B1 polymorphisms (Akarsu et al., 2002, Sutter et al., 2005, Fan et al., 2004) in our patients: g.3947C $>$ G, g.4160G $>$ T, g.8131C>G, g.8184C>T, g.8195A>G. (Table II). The most frequent haplotype in individuals with CYP1B1 mutations is 5'-C-G-G-T-A-3', as already described in other populations (Belmouden et al.,2002, Kaur et al., 2005, Bejjani et al., 1998, Stoilov et al., 2001). This haplotype is present in 41 of the 44 mutated alleles $(93 \%)$, and in only 20 of the remaining 100 wild type alleles $(20 \%)$; the difference is statistically significant $(\mathrm{Q} 2=22.23, \mathrm{p}<0.0001, \mathrm{CI} 95 \% 0.555-0.905)$.

Considering the seventeen mutations we found, fifteen are linked to the $5^{\prime}-\mathrm{C}-\mathrm{G}-\mathrm{G}-\mathrm{T}-\mathrm{A}-3^{\prime}$ haplotype and two (E387K and R390S) are associated with two other different haplotypes.

\subsection{MYOC/TIGR gene analysis}

The report in published papers of patients with mutations in either CYP1B1 and MYOC genes prompted us to look for MYOC/TIGR variations in the six patients having only one mutation in CYP1B1. 


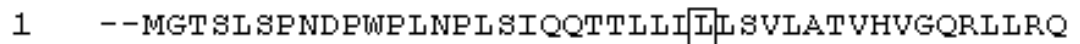

42

1 - MLT GLGEDAFLQF GAL SAQQTTLII IT SVLAAVHAGQWLLRQ

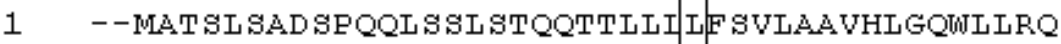

42

1 - WALERLGEALRGTPPL-- QSGLLI LUCLLAAVHLGKLLLQR.

39

1 -WLAALIYTILAILL GVLAT BYICITYGVKRR VLQFVRTNGTE

4.3

43

R--RRQ-LRGAHEGPFAITPIIGNA_A_VGQA_AHLSF- - - - - -

74

43

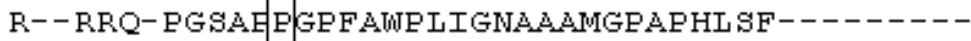

74

43

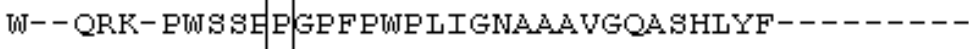

74

40 RRWRRQGQRLAH FF FWTFLIGNAAQLGSAFHLAF EKLGGAFHQ

83

44

INHNAYQKYTQAEGERTWIIGNLHLLDRYRDGEFAG-------

80

75 - ARLARRYGDVFOIRLGGCFIVULNGERAIHOAWVQQGBAFAD

75 - -ARLARRYGDVFOIRLGSCRVVVLNGERAIRO

75 - ARLARPYGDVFOIRLGBCEVUVLNGESAIHQ

116

84 GLARLAGTYGAVFOLRGGRTEVVVUNGESAIROAWVRQGAAFAG

81 -FTALAQQYGDIYBLTFGHTRCLVVNWLELIREUHONGKVMGG

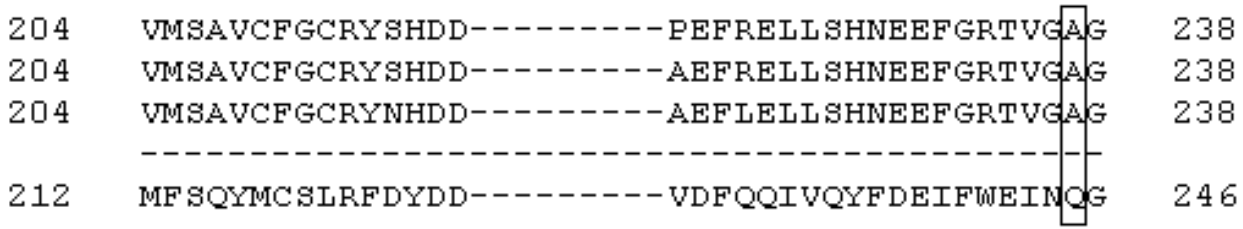

409 - - VLGYHIPKDTUVF VNQWTUNHDE UKWTN-PENFDEARFLDK 448

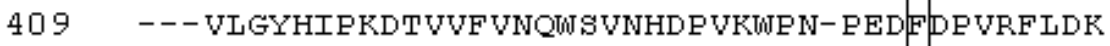
448

409 - - VLGYYIFKNTVUF VNQTOSUNHDFAKTEN-FEDFDEARFLDK 448

285 ---IMGYLIPKDTVIFUNQTSUNHDEAKTIN-EEDFDFTRFLDE 324

404 - - IGGYGVTKGTIVFINNYULNTGEKFTUN-EREENELRFLEF 443

Fig. 1. Aminoacidic Sequence Alignment of CYP1B1 and homolous genes in Eukariota. Lane 1:CYP1B1 H.sapiens, lane 2 LOC483038 C.familiaris, lane 3: Cyp1b1 M.musculus, lane 4: LOC421466 G.gallus, lane 5: spo D.melanogaster. 


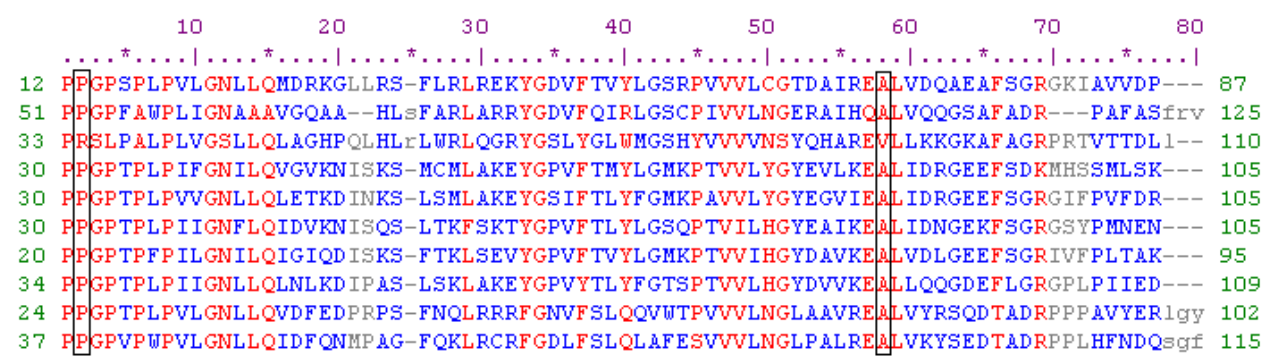

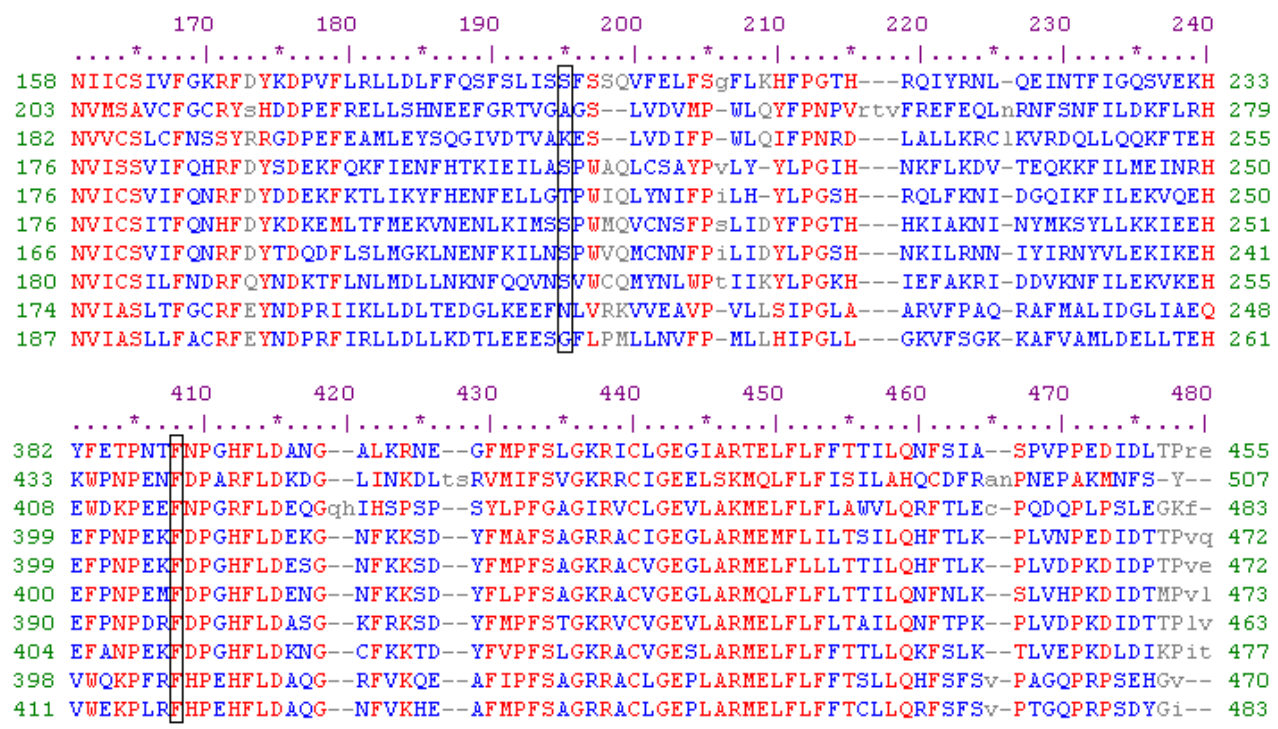

Fig. 2. Aminoacidic Sequence Alignment of CYP1B1 (second lane) and other P450 family members (CYP2b4, CYP17A1, CYP2C22, CYP2C3, CYP2C7, CYP2C1, CYP2C23, CYP2D14, CYP2D4) .

The analysis of the complete MYOC gene sequence identified, in three patients, two transitions (G>A at 249 and $\mathrm{C}>\mathrm{T}$ at 1362 cDNA positions) causing the two aminoacidic variations $\mathrm{R} 76 \mathrm{~K}$ and $\mathrm{A} 447 \mathrm{~V}$. Lysine in position 76 is similar to Arginine; Valine in position 447, an aminoacid with a large aliphatic hydrophobic side chain, usually located inside the protein, substitutes Alanine that has only small steric limits and can be located in the hydrophilic areas either outside or in the hydrophobic areas inside the protein.

In patient 42 the A447V is present with the G61E common CYP1B1 mutation; two mutations are distinctly inherited from the two parents. Patient 132, with a single maternally transmitted CYP1B1 G61E mutation, inherited R76K from the father while patient 203 received both the R76K and the CYP1B1 A443G from the unaffected father, who is homozygotes for R76K.

To confirm the polymorphic role of R76K, already suggested in literature (Colomb et al., 2003, Edward et al., 2004), we analyzed 100 chromosomes in a random Italian population, obtaining a frequency of 0,125 and 0,875 for the A and G alleles respectively. 


\section{Discussion}

Molecular analysis of the CYP1B1 gene performed on 72 Italian patients with found eighteen different variations in $25(34.7 \%)$ individuals. Four of these variations (L26R, P52L, A106D, A237E) are reported here for the first time and produced a non synonymous aminoacidic change. Their pathological role in CG development could be an explanation for the significant changes in the protein caused by the aminoacidic substitutions in Eukariota and cytochrome P450 family conserved regions. The new changes are in a compound heterozygous state with already described pathological mutations and are distributed in exon \# 2 and 3.

The conservative aminoacid change F440L always found in cis with the P52L in 4 subjects, both in patients (with another CYP1B1 mutation) and in healthy carriers, could be classified as a rare polymorphism linked to the pathological P52L.

One of the two nucleotide variants we identified in the untranslated exon 1 had not been previously reported. In patient 91 a C to A at position 226cDNA was found combined with the pathological mutation 1236-1237insC. The presence in cis with the CG mutation also in the unaffected mother suggests that this ex1UTR variation does not play a pathological role in CG development.

We identified two new synonymous changes ( $\mathrm{G}>\mathrm{A}$ at the Glutamic Acid in position 359 and $\mathrm{C}>\mathrm{T}$ at the Valine in position 363) in 2 different patients. These variations do not introduce aminoacidic changes and were not found in 100 analyzed chromosomes, so we can consider them as rare polymorphisms.

Clinical evaluation of patients cannot show a particular phenotype-genotype correlation even if mutations that produce truncated proteins seem more frequent in patients with a disease onset before the first year of life and more then two surgical procedures.

As also described in Indian and Saudi Arabian populations, we identified the M1T and W57X CYP1B1 mutations that have been previously associated only with Peters' anomaly, in three of our CG patients. These results support the concept that distinct CYP1B1 mutations are not responsible for the two different diseases and that a specific phenotype could result from interactions between CYP1B1 and other modifier genes.

The previously described CYP1B1 intragenic polymorphisms (R48G, A119S, L432V, D449D and N453S) were analyzed and the most frequent haplotype (93\%) among affected individuals with CYP1B1 mutations appears to be 5'-C-G-G-T-A-3', which has been associated with fifteen different mutations. This particular haplotype was also observed in 94.7\% of the Saudi Arabian and in the majority of the Brazilian CG chromosomes. Interestingly, in our 47 CG patients without mutations in CYP1B1, the frequency of the 5'-CG-G-T-A-3' haplotype is the same as the general Italian population ( $23 \%$ vs $20 \%)$. The association of this specific uncommon haplotype with the majority of CYP1B1 mutations in geographically and ethnically distinct populations could confirm the hypothesis that this DNA sequence predisposes the gene to mutational events as already suggested.

The presence in other populations of patients with mutations in both CYP1B1 and MYOC genes prompted us to analyze the six patients that had only one mutation in CYP1B1 for the presence of MYOC/TIGR variations. The R76K was found in compound heterozygosis in patient 132 and 203 with the G61E and A443G CYP1B1 mutations respectively. The presence of MYOC R76K aminoacidic change in both alleles of patient 203's unaffected father, who also had a CYP1B1 mutation, defines the non pathological role of this variation, confirmed as a polymorphism in an Italian population frequency of 0.125 and 0.875 for the A and G alleles respectively. 
In patient 42 we found, in double heterozygous status with the CYP1B1 G61E, the new MYOC variation A447V. This substitution affects a conserved aminoacidic position and introduces a residue with peculiar characteristics that can alter the protein functions. The two mutations are distinctly inherited from the unaffected heterozygous parents and the A447V was not found in 100 control chromosomes. This is the first report of CYP1B1 and MYOC mutations in Italian patients with congenital glaucoma.

The molecular characterisation of both CYP1B1 and MYOC/TIGR genes in affected subjects allowed us to better clarify the genetic basis of the CG disease. Our results confirm the major role of CYP1B1 in congenital glaucoma and also support an autosomic recessive role of MYOC/TIGR gene in a digenic inheritance model. The presence of only one CYP1B1 mutation in 5 patients confirms that other genes could interact with the function of the CYP1B1 codified protein in CG onset with different digenic inheritances. We did not look for and we did not find any genotype and phenotype correlations in our patients (Hollander et al., 2006). A study of Iranian patients did not find any myocilin mutations as cause of congenital glaucoma (Elahi et al., 2010).

\section{Acknowledgements}

The Author wants to thank the whole staff of Medical Genetics Institute - Catholic University of Roma, Roma, Italy- EU.

\section{References}

Akarsu AN, Turacli ME, Aktan GS et al.(1996). A second locus (GLC3B) for primary congenital glaucoma (buphthalmos) maps to the 1 p36 region. Hum Mol Gen, 5: 1199-203.

Antonarakis S and the Nomenclature Working group (1998). Hum Mut; 11:1-3.

Bejjani BA, Lewis RA, Tomey KF, Anderson KL, Dueker DK, Jabak M, Astle WF, Otterud B, Leppert M, Lupski JR.(1998) Related Articles, Links Mutations in CYP1B1, the gene for cytochrome P4501B1, are the predominant cause of primary congenital glaucoma in Saudi Arabia. Am J Hum Genet. 62(2):325-33.

Bejjani B A, Stockton DW, Lewis RA, Tomey KF, Dueker DK, Jabak M, Astle WF, Lupski JR(2000). Multiple CYP1B1 mutations and incomplete penetrance in an inbred population segregating primary congenital glaucoma suggest frequent de novo events and a dominant modifier locus. Hum. Molec. Genet. 9: 367-74.

Belmouden A, Melki R, Hamdani M et al.(2002). A novel frameshift founder mutation in the cytochrome P450 1B1 (CYP1B1) gene is associated with primary congenital glaucoma in Morocco. Clin Genet; 62: 334-9.

Bruttini M, Longo I, Frezzotti P et al.(2003): Mutations in the myocilin gene in families with primary open-angle glaucoma and juvenile open-angle glaucoma. Arch Ophthalmol; 121: 1034-8.

Chakrabarti S, Kaur K, Komatireddy S, Acharya M, Devi KR, Mukhopadhyay A, Mandal AK, Hasnain SE, Chandrasekhar G, Thomas R, Ray K.(2005). Gln48His is the prevalent myocilin mutation in primary open-angle and primary congenital glaucoma phenotypes in India. Mol Vis. 4;11:111-3.

Colomb E, Kaplan J, Garchon HJ (2003). Novel cytochrome P4501B1 (CYP1B1) mutations in patients with primary congenital glaucoma in France. Hum Mut ; 22 (6): 496. 
Edward D, Al Rajhi A, Lewis RA, Curry S, Wang Z, Bejjani B.(2004). Molecular basis of Peters anomaly in Saudi Arabia.Ophthalmic Genet.; 25 (4):257-70.

Elahi E, Narooe-Nejhad M, Suri F and Yazdani F(2010): Myocilin mutations are not a major cause of primary congenital glaucoma in Iranian patients. J Opthalmic Vis Res.; 5 (2): 101-4.

Fan BJ, Leung YF, Pang CP, Baum L, Tam OS, Wang N, Lam SC(2004). Single nucleotide polymorphisms of the myocilin gene in primary open-angle glaucoma patients. Zhonghua Yi Xue Yi Chuan Xue Za Zhi. ;21(1): 70-3. Chinese.

Hayes CL, Spink DC, Spink BC, Cao JQ, Walker NJ, Sutter TR.(1997). 17ß-estradiol hydroxylation catalyzed by cytochrome P4501B1. Proc Natl Acad Sci USA, 93: 977681.

Hollander DA, Sarfarazi M, Stoilov I et al.(2006). Genotype and phenotype correlations in congenital glaucoma. Trans Am Ophthalmol Soc. , 104: 183-95.

Kaur K, Reddy AB, Mukhopadhyay A, Mandal AK, Hasnain SE, Ray K, Thomas R, Balasubramanian D, Chakrabarti S (2005). Myocilin gene implicated in primary congenital glaucoma. Clin Genet. ;67(4):335-40.

Lee WB, Brandt JD, Mannis MJ et al.(2003). Aniridia and Brachmann-de Lange syndrome: a review of ocular surface and anterior segment findings. Cornea; 22 (2): 178-80.

Libby RT, Smith RS, Savinova OV et al.(2003). Modification of ocular defects in mouse developmental glaucoma models by tyrosinase. Science, vol. 299, 1578-81.

Mandal AK, Hornby SJ, Jones RB.(2002). Congenital hydrocephalus associated with congenital glaucoma and natal teeth. Indian J Ophthalmol ; 50 (4): 322-3.

Mashima Y, Suzuki Y, Sergeev Y, Ohtake Y, Tanino T, Kimura I, Miyata H, Aihara M, Tanihara H, Inatani M, Azuma N, Iwata T, Araie M.(2001). Novel cytochrome P4501B1 (CYP1B1) gene mutations in Japanese patients with primary congenital glaucoma. Invest Ophthalmol Vis Sci. 2001 Sep;42(10):2211-6. Erratum in: Invest Ophthalmol Vis Sci;42(12):2775.

Ming, JE., Muenke, M(2002). Multiple hits during early embryonic development: digenic diseases and holoprosencephaly. Am. J. Hum. Genet., 71: 1017-32.

Ohtake Y, Tanino T, Suzuki Y et al.(2003). Phenotype of cytochrome P4501B1 gene (CYP1B1) mutations in Japanese patients with primary congenital glaucoma. Br J Ophthalmol.; 87: 302-4.

Ray K, Mukhopadhyay A, Acharya M(2003). Recent advances in molecular genetics of glaucoma. Mol Cell Biochem ; 253 (1-2): 223-31.

Sarfarazi M, Akarsu, AN, Hossain, A, et al(1995).Assignment of a locus (GLC3A) for primary congenital glaucoma (buphthalmos) to 2 p21 and evidence for genetic heterogeneity. Genomics , 30: 171-7.

Stoilov I, Akarsu AN, Sarfarazi, M(1997). Identification of three different truncating mutations in the cytochrome P4501B1 (CYP1B1) gene as the principal cause of primary congenital glaucoma (buphthalmos) in families linked to the GLC3A locus on chromosome 2p21. Hum Mol Gen , 6: 641-7.

Stoilov I, Akarsu AN, Alozie I, Child A, Barsoum-Homsy M, Turacli ME, Or M, Lewis RA, Ozdemir N, Brice G, Aktan SG, Chevrette L, Coca-Prados M, Sarfarazi, M(1998): Sequence analysis and homology modeling suggest that primary congenital glaucoma on 2 p21 results from mutations disrupting either the hinge region or the conserved core structures of cytochrome P4501B1. Am. J. Hum. Genet. , 62: 573-84. 
Stoilov I, Jansson I, Sarfarazi M, Schenkman JB.(2001). Roles of cytochrome P450 in development. Drug Metab Drug Interact, 18: 33-55.

Stoilov IR, Costa VP, Vasconcellos JPC et al.(2002). Molecular genetics of primary congenital glaucoma in Brazil. Invest Ophthalmol Vis Sci ; 43: 1820-7.

Sutter TR, Tang YM, Hayes CL, Wo Y-YP, Jabs EW, Li X, Yin H, Cody C W, Greenlee $\mathrm{WF}(1994)$. Complete cDNA sequence of a human dioxin-inducible mRNA identifies a new gene subfamily of cytochrome P450 that maps to chromosome 2. J. Biol. Chem , 269: 13092-9.

Vincent A, Billingsley G, Priston M, Williams-Lyn D, Sutherland J, Glaser T, Oliver E, Walter MA, Heathcote G, Levin A, Heon E(2001). Related Articles, Links Phenotypic heterogeneity of CYP1B1: mutations in a patient with Peters' anomaly. J Med Genet.;38(5): 324-6.

Vincent AL, Billingsley G, Buys Y, Levin AV, Priston M, Trope G, Williams-Lyn D, Heon $\mathrm{E}(2002)$. Digenic inheritance of early-onset glaucoma: CYP1B1, a potential modifier gene. Am J Hum Genet.;70(2):448-60.

Weisschuh N, Schiefer U(2003). Progress in the genetics of glaucoma. Dev Ophthalmol ; 37: 83-93.

Zhang QY, Dunbar D, Kaminsky L(2000). Human cytochrome P-450 metabolism of retinals to retinoic acids. Drug Metab Disp , 28: 292-7. 


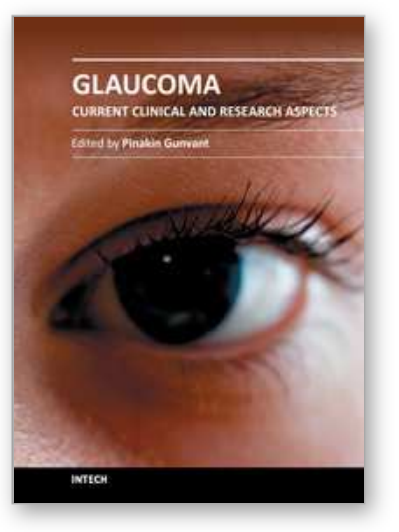

\author{
Glaucoma - Current Clinical and Research Aspects \\ Edited by Dr. Pinakin Gunvant
}

ISBN 978-953-307-263-0

Hard cover, 376 pages

Publisher InTech

Published online 09, November, 2011

Published in print edition November, 2011

This book summarizes current literature about research and clinical science in glaucoma and it is a synopsis and translation of the research conducted by individuals who are known in each of their respective areas. The book is divided into two broad sections: basic science and clinical science. The basic science section examines bench- and animal-modeling research in an attempt to understand the pathogenesis of glaucoma. The clinical science section addresses various diagnostic issues and the medical, laser and surgical techniques used in glaucoma management.

\title{
How to reference
}

In order to correctly reference this scholarly work, feel free to copy and paste the following:

Italo Giuffre' (2011). Molecular Analysis of Italian Patients with Congenital Glaucoma, Glaucoma - Current Clinical and Research Aspects, Dr. Pinakin Gunvant (Ed.), ISBN: 978-953-307-263-0, InTech, Available from: http://www.intechopen.com/books/glaucoma-current-clinical-and-research-aspects/molecular-analysis-ofitalian-patients-with-congenital-glaucoma

\section{INTECH}

open science | open minds

\section{InTech Europe}

University Campus STeP Ri

Slavka Krautzeka 83/A

51000 Rijeka, Croatia

Phone: +385 (51) 770447

Fax: +385 (51) 686166

www.intechopen.com

\section{InTech China}

Unit 405, Office Block, Hotel Equatorial Shanghai

No.65, Yan An Road (West), Shanghai, 200040, China

中国上海市延安西路65号上海国际贵都大饭店办公楼 405 单元

Phone: +86-21-62489820

Fax: +86-21-62489821 
(C) 2011 The Author(s). Licensee IntechOpen. This is an open access article distributed under the terms of the Creative Commons Attribution 3.0 License, which permits unrestricted use, distribution, and reproduction in any medium, provided the original work is properly cited. 